\title{
Research and analysis of production safety regulations for building and sanitary ceramic enterprises
}

\author{
Shanyu Liu ${ }^{1}$, Kaifang Wang ${ }^{1}$, Yunli Wang ${ }^{2}$, Haibo Dang ${ }^{1}$, Fan Zhang ${ }^{1 *}$ \\ ${ }^{1}$ China Building Material Test \& Certification Group (Shaanxi) Co. Ltd, Xi'an, Shaanxi, 710049, China \\ ${ }^{2}$ Xi'an University of Technology No.5, Jinhua South Road, Beilin District, Xi'an City, Shaanxi Province 710048, China
}

\begin{abstract}
Production safety standards are the foundation of industry safety supervision, the basic requirements and measurement scales for production enterprises to achieve management standardization, onsite standardization, and operation standardization. They are the foundation for the construction and sanitary ceramics industry to consolidate safety management, improve the intrinsic safety of equipment, and strengthen personnel safety awareness, The implementation of the main responsibility of enterprise safety production and the necessary requirements for building a long-term safety production mechanism are also the basic work of safety development. This article mainly studies and analyzes the current situation of production safety in the construction and sanitary ceramics industry and the overall situation of the existing safety production standards in this industry. Summarized the necessity and urgency of implementing the production safety regulations of building and sanitary ceramics enterprises.
\end{abstract}

\section{Introduction}

My country is a big country in the production and consumption of building and sanitary ceramics. However, in terms of the overall level of the building and sanitary ceramics industry, the variety and quality, technical equipment, test methods, and process research of my country's building and sanitary ceramics are still relatively low compared to those of foreign advanced building and sanitary ceramics There are large gaps and shortcomings, product prices are low, and economic benefits are not high.

Countries in the "Twelfth Five-Year Plan" plan are also making gradual adjustments to their economic growth methods at the macro level, with more emphasis on achieving rapid economic growth on the basis of protecting the environment and resources. As a ceramic industry that has always been called the "three highs" of high energy consumption, high pollution, and high consumption by the outside world, it is incompatible with the current economic development of the country. Although the current economic growth rate of the ceramic industry is very fast, there are still economic growth structures. A reasonable phenomenon is that the consumption of resources is the point of economic growth. Moreover, the exchange of economic growth at the cost of resource consumption does not meet the requirements of sustainable development.

Building sanitary ceramics is an industry with high energy consumption and high resource consumption, which has caused irreconcilable contradictions with my country's national conditions of resource shortage, energy shortage, and high environmental pressure. The ceramic industry has been listed as one of the six key industries in the country for energy conservation and emission reduction. The "Access Standards for Building and Sanitary Ceramics Industry" issued by the state puts forward more urgent requirements for the transformation and upgrading of the building and sanitary industry. The use of new technologies and new equipment to achieve high-efficiency and clean production methods such as low energy consumption, light emission, intelligent equipment and digitalization in the ceramic production process is an inevitable choice for the future development of my country's ceramic industry.

\section{Investigation of safety accidents in industry production}

We investigated some ceramic manufacturers. The accident level classification is shown in Table 1. The types of accidents are shown in Table 2. 
Table1. Classification of accident levels

\begin{tabular}{|c|c|c|c|}
\hline Accident level & Minimum & Death & Injured \\
\hline Major accident & 4 & 13 & 26 \\
\hline General accident & 12 & 14 & 57 \\
\hline Subtotal & 15 & 27 & 83 \\
\hline
\end{tabular}

Table2. Classification of accident types

\begin{tabular}{|c|c|c|c|}
\hline Type of accident & Occurrence & The proportion & $\begin{array}{c}\text { Whether it comes from safety } \\
\text { hazards and sources of danger }\end{array}$ \\
\hline explosion & 9 & $60 \%$ & Yes \\
\hline mechanical & 2 & $13.3 \%$ & Yes \\
\hline pneumoconiosis & 1 & $6.7 \%$ & Yes \\
\hline come down & 2 & $13.3 \%$ & Yes \\
\hline Electric shock & 1 & $6.7 \%$ & natural disaster \\
\hline Oil depot & 0 & 0 & 0 \\
\hline wind and rain & 0 & $10 \%$ & \\
\hline total & 15 & & \\
\hline
\end{tabular}

It can be seen that in recent years, the overall situation of safety production in the building and sanitary ceramics industry has been relatively stable. However, major accidents have risen, and the safety production situation remains grim.

The building and sanitary ceramics industry has the characteristics of multiple product categories, diversified production processes, diversified fuels, diversified kilns, more dust, and loud noise. In addition, due to the low concentration of the industry, most non-public enterprises and small and medium-sized enterprises exist[1]. And the particularity of enterprises employing a large number of migrant workers has increased the difficulty of industry safety supervision and management. In recent years, due to the weakening of industry management, the inadequate safety supervision work, and the weak production and management concepts of a large number of private enterprises that have entered, the establishment of industry safety management institutions is not perfect, the full-time safety management staff is insufficient, the rules and regulations are lacking, and the responsibility Failure to implement, insufficient investment in safety, imperfect management of major hazards, inadequate emergency response work, increased occupational hazards and other issues are more prominent, and major fatal accidents occur from time to time[2]. Therefore, the safety production situation in the building and sanitary ceramic industry is still severe.

Compared with large ceramic companies, small and medium ceramic companies have problems such as incomplete safety supervision departments, imperfect safety production systems, insufficient safety investment[3], and frequent production safety accidents. Typical accident cases as follows:
Case 1: A big explosion occurred at the gas station of Shandong Zibo Stanker Ceramics Company. The accident caused 3 deaths and 8 injuries. Figure 1 shows the scene of a gas station explosion accident.

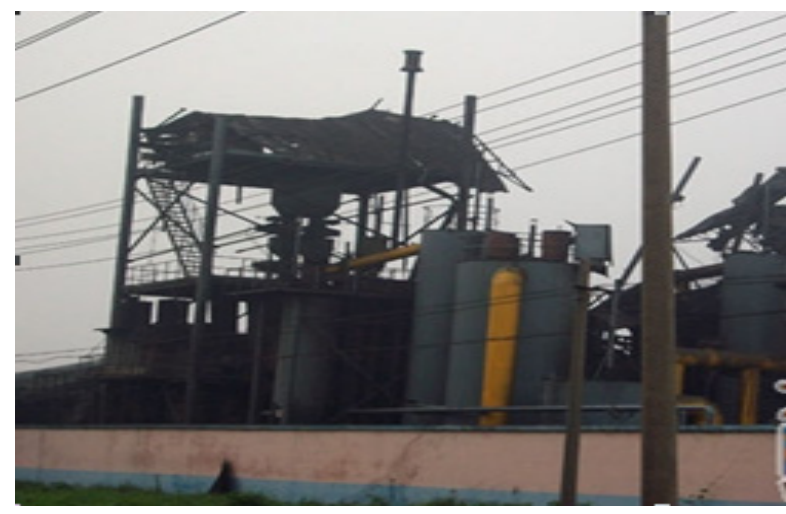

Fig 1. The scene of the spray drying tower explosion accident

Case 2: Beijing Yingkeer Ceramic Wear-resistant Products Co., Ltd. near Taihu Town, Tongzhou District, Beijing deflagrated[4], causing 2 deaths and 1 injury. The chemical that allegedly caused the deflagration was alumina powder. Figure 2 shows the place where the explosion occurred. 


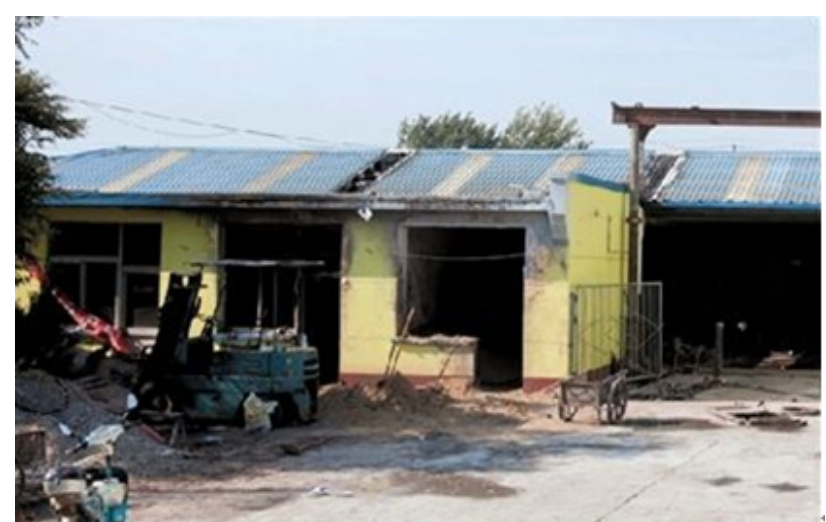

Fig 2. Location of explosion accident

Case 3: The gas station of Jingyu Ceramics Co., Ltd. in Enping City, Guangdong Province exploded due to violation of operating procedures, causing 1 death and 2 injuries. Figure 3 shows the scene of the explosion accident[5].

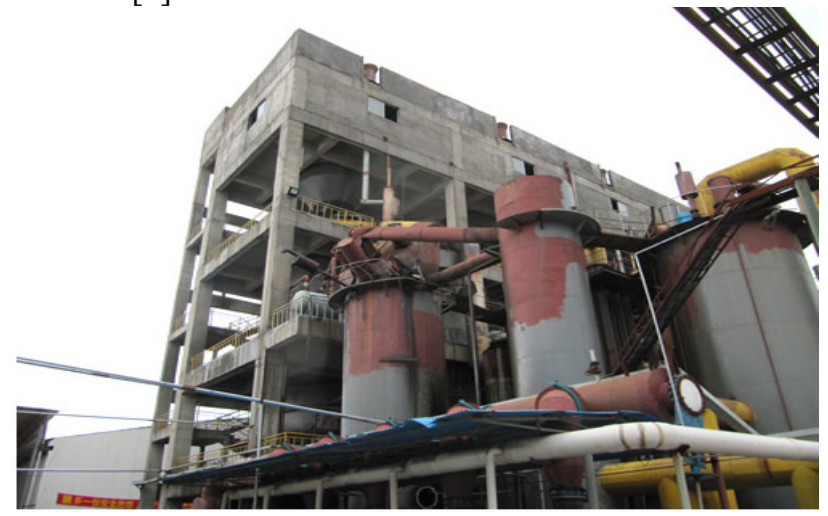

Fig 3. The scene of the explosion accident

Case 4: A gas spray drying tower in a raw material workshop of Xinwanxing Porcelain Co., Ltd. in Qichun County, Hubei Province exploded, causing 4 deaths and 13 injuries. Figure 4 shows the explosion accident scene of the spray drying tower.

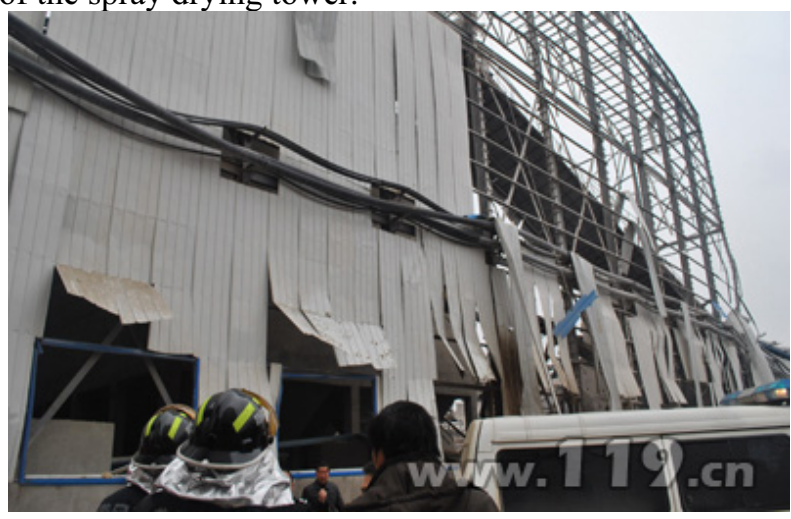

Fig 4. The scene of the spray drying tower explosion accident

From the perspective of typical accident cases, one of the most important reasons for the explosion is the air leakage of the equipment. The equipment design, material selection, installation and construction should be strictly checked. Secondly, mechanical injuries are mostly caused by improper operation. Employees should be educated to strictly follow the operating procedures. In terms of silicosis, although there are dust masks and the like, it is necessary to research and develop high-efficiency protective equipment and equipment. Some enterprises have workers who are not aware of self-protection and are unwilling to wear dust-proof products. Some corporate leaders do not pay attention to safety issues[6]. For example, the person in charge of the electricity used by a certain company does not have a job certificate.

\section{The overall situation of existing safety production standards in the industry}

The safety technical standards for the building and sanitary ceramics industry have not yet been systematically matched, and there are still many missing items, and safety management standards are relatively lacking. Currently, there are 48 safety standards for the building and sanitary ceramics industry, including 39 national standards and 9 industry standards. Among the national standards, there are 35 basic general standards, 1 safety management standard, 3 safety technical standards, 4 basic general standards, 1 safety management standard, and 4 safety technical standards in the industry standard, the proportions of the three in national standards and industry standards are shown in Figure 5 and Figure 6, respectively.

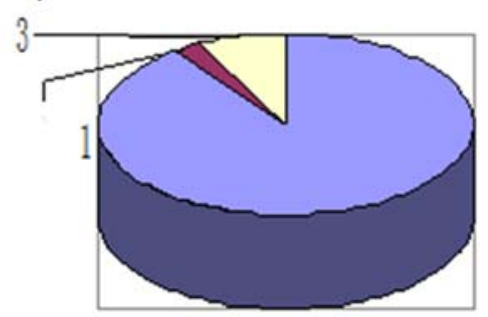

35

Fig 5. Distribution of national standards for safe production

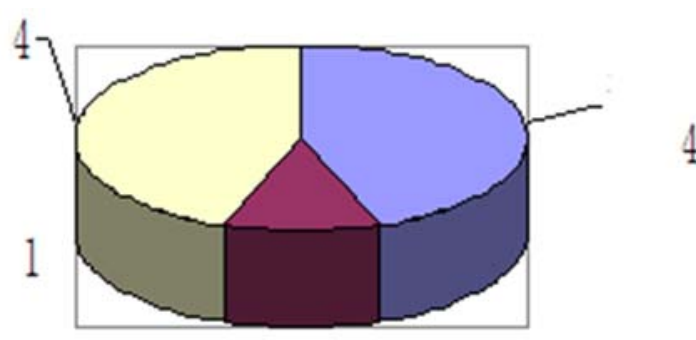

Fig 6. Distribution of standard types of production safety industry

\section{Conclusion}

Through the effective implementation of the safety standard system of the building and sanitary ceramics industry, the whole process of ceramic production can be standardized and standardized, and it can provide the technical basis and technical guarantee for the control target for ceramic quality and production safety, and realize the safety of each key link and key factor of ceramic production. Effective monitoring, meeting the regulations and requirements of ceramic safety standards, 
and comprehensively guaranteeing and improving the safety level of the ceramic industry.

\section{References}

1. Deng Zhuming, Gou Li, ran Junguo. Rheological properties of Yb: YAG laser ceramic slurry prepared by grouting [J]. Silicate bulletin, 2013,32 (02): 221$224+230$.

2. World Bank. The National Quality Infrastructure [R], 2013.

3. Wu Xie, Chen Zhenhua, Li Fuying. Preparation of alumina ceramic elbow by grouting method [J]. China ceramics, 2011,47 (08): 50-53.

4. KorhanKo et al.(2020)Is Support Vector Regression method suitable for predicting rate of penetration. Journal of Petroleum Science and Engineering.Vol 194, pp. 19-24.

5. World Bank. The National Quality Infrastructure [R], 2013.

6. Nie Baomin. Development and direction of China's sanitary ceramics industry [J]. Ceramics, 2011 (04): 21-24. 